\title{
Prevalence of hepatitis B, hepatitis C and human immunodeficiency viral infections in patients with inflammatory bowel disease in north India
}

\author{
Parnita Harsh ${ }^{1}$, Vipin Gupta ${ }^{2}$, Saurabh Kedia ${ }^{2}$, Sawan Bopanna ${ }^{2}$, Sucharita Pilli ${ }^{2}$, Surendernath $^{2}$, \\ Govind Kumar Makharia ${ }^{2}$, Vineet Ahuja ${ }^{2}$ \\ ${ }^{I}$ Department of Molecular and Cell Biology, University of Illinois at Urbana-Champaign, Champaign, IL, USA, ${ }^{2}$ Department of \\ Gastroenterology, All India Institute of Medical Sciences, New Delhi, India
}

\begin{abstract}
Background/Aims: Patients with inflammatory bowel disease (IBD) often require immunosuppressive therapy and blood transfusions and therefore are at a high risk of contracting infections due to hepatitis B (HBV) and hepatitis C (HCV) and human immunodeficiency virus (HIV). In the present study, we assessed the prevalence of these infections in patients with IBD. Methods: This retrospective study included 908 consecutive patients with IBD (ulcerative colitis [UC], n=581; Crohn's disease $[\mathrm{CD}], \mathrm{n}=327$ ) who were receiving care at a tertiary care center. Ninety-five patients with intestinal tuberculosis (ITB) were recruited as disease controls. Prospectively maintained patient databases were reviewed for the prevalence of HBV surface antigen, anti-HCV antibodies, and HIV (enzyme-linked immunosorbent assay method). HCV RNA was examined in patients who tested positive for anti-HCV antibodies. Prevalence data of the study were compared with that of the general Indian population (HBV, 3.7\%; HCV, 1\%; HIV, 0.3\%). Results: The prevalence of HBV, HCV, and HIV was $2.4 \%, 1.4 \%$, and $0.1 \%$, respectively, in the 908 patients with IBD. Among the 581 patients with UC, 2.2\% (12/541) had HBV, 1.7\% (9/517) had HCV, and 0.2\% (1/499) had HIV. Among the 327 patients with CD, 2.8\% (8/288) had HBV, 0.7\% (2/273) had HCV, and 0\% (0/277) had HIV. One patient with CD had HBV and HCV coinfection. The prevalence of HBV, HCV, and HIV in patients with ITB was 5.9\% (4/67), 1.8\% (1/57), and 1.2\% (1/84), respectively. Conclusions: The prevalence of HBV, HCV, and HIV in north Indian patients with IBD is similar to the prevalence of these viruses in the general community. Nonetheless, the high risk of flare after immunosuppressive therapy mandates routine screening of patients with IBD for viral markers. (Intest Res 2017;15:97-102)
\end{abstract}

Key Words: Inflammatory bowel disease; Colitis, ulcerative; Crohn disease; Hepatitis B; Hepatitis C

\section{INTRODUCTION}

The disease burden of IBD has increased significantly in India in the last few decades. ${ }^{1}$ Patients with IBD are more likely to undergo surgery and receive blood transfusions and therefore are at a high risk of contracting blood-borne

Received March 28, 2016. Revised July 3, 2016

Accepted July 14, 2016.

Correspondence to Vineet Ahuja, Department of Gastroenterology, All India Institute of Medical Sciences, Room No. 3093, Third Floor, Teaching Block,

New Delhi 110029, India. Tel: +91-11-26593300, Fax: +91-11-2658663,

E-mail:vins_ahuja@hotmail.com

Financial support: None. Conflict of interest: None. infections such as those caused by HBV and HCV and human immunodeficiency virus (HIV). Additionally, patients with IBD are likely to receive immunosuppressive therapy, which affects the course of these infections. ${ }^{2}$ Although HBV and HCV do not affect the natural course of IBD, HIV is well recognized to do so. ${ }^{3}$ Currently available data on the prevalence of these blood-borne infections are inadequate and inconsistent among different studies. Thus, the objective of the present study was to determine the prevalence of $\mathrm{HBV}$, $\mathrm{HCV}$, and HIV infection in patients with IBD (UC and CD) attending a tertiary referral hospital in north India.

\footnotetext{
(c) Copyright 2017. Korean Association for the Study of Intestinal Diseases. All rights reserved.

This is an Open Access article distributed under the terms of the Creative Commons Attribution Non-Commercial License (http://creativecommons.org/licenses/by-nc/4.0)

which permits unrestricted non-commercial use, distribution, and reproduction in any medium, provided the original work is properly cited.
} 


\section{METHODS}

\section{Patient Population}

Patients with IBD who visited the Inflammatory Bowel Disease Clinic at All India Institute of Medical Sciences (AIIMS), New Delhi, from August 2004 to January 2016 were enrolled in this study. AIIMS is a tertiary care center serving as a referral hospital for patients from all over north India. Patients with intestinal tuberculosis (ITB) were enrolled as disease controls.

\section{Study Design}

This study involves a retrospective analysis of a referral IBD registry. Relevant clinical data were obtained from medical records pertaining to both the initial consultation and subsequent follow-up consultations throughout care within the practice. Prospectively maintained data included detailed information on the patient's disease and follow-up, including name, age, sex, address, diagnosis, medical history, results of clinical examination and laboratory investigations and ongoing treatment.

\section{Diagnosis of Viral Infections}

Data regarding the prevalence of viral infections (HBV, $\mathrm{HCV}$, and HIV) were obtained from routinely performed ELISA-based serological tests for HBsAg, anti-HCV antibodies, and HIV for all patients at our center. However, all three viral markers were not available for all the patients in database. All patients who tested positive for anti-HCV antibodies underwent quantitative HCV RNA testing for confirmation. Patients with HBsAg positivity were diagnosed with HBV infection, and no confirmatory test was required. HIV serology was tested and reported as positive according to the guidelines of the National AIDS Control Organization (NACO). ${ }^{4}$

\section{Prevalence of Viral Infections in the General Population}

Data on the prevalence of HCV and HBV infection in the general population were obtained from the National Centre for Disease Control (NCDC) website. ${ }^{5}$ NACO data were used to determine the prevalence of HIV in the general population. ${ }^{4}$ In India, the hepatitis B vaccine has been covered under the Universal Immunization Programme since 2007, with a total of four doses administered at birth and then at 6 ,
10, and 14 weeks of age. However, the vaccination status of the patients in the current study could not be determined.

\section{Data Analysis}

The prevalence of the viral infections was recorded as percentages. Data were analyzed using Stata software (version 11.2; StataCorp LP, College Station, TX, USA). The prevalence of the three blood-borne infections was compared between patients with IBD and the general population by using the one-sample proportion test. The $P$-values less than 0.05 were considered statistically significant.

\section{RESULTS}

A total of 908 patients with IBD were enrolled at the IBD clinic of AIIMS between August 2004 and January 2016. Of these, 581 were diagnosed with UC (male, $n=340$; female, $\mathrm{n}=241$; mean age, $36.9 \pm 11.7$ years) and 327 were diagnosed with $\mathrm{CD}$ (male, $\mathrm{n}=201$; female, $\mathrm{n}=126$; mean age, $39.1 \pm 13.9$ years).

\section{Prevalence of HBV, HCV, and HIV Infection in Patients with IBD}

According to NACO and NCDC data, the prevalence of $\mathrm{HBV}, \mathrm{HCV}$, and HIV in the general population in India is $3.7 \%$, $1 \%$, and $0.3 \%$, respectively. In our study, we found that the prevalence of $\mathrm{HBV}, \mathrm{HCV}$, and HIV among the 908 patients with IBD (UC and CD) was 2.4\% (20/829), 1.4\% (11/790), and $0.1 \%(1 / 776)$, respectively. All three viral markers of all the patients were not available in the database. This led to different denominators while calculating prevalence of these infections in IBD patients.

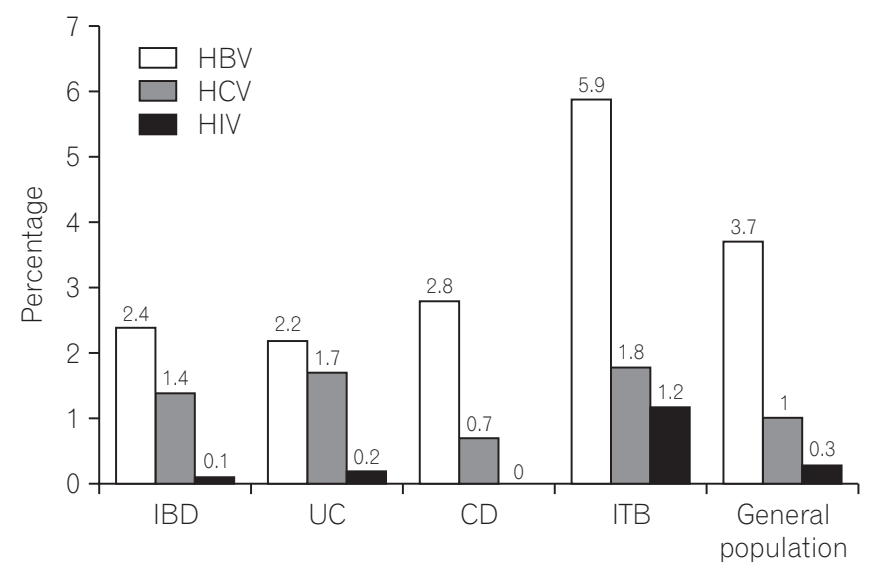

Fig. 1. Prevalence of $H B V, H C V$, and human immunodeficiency virus (HIV) in patients with IBD or intestinal tuberculosis (ITB). 
When compared to prevalence of these infections in general population, the results were not statistically significant ( $P=0.05, P=0.26$, and $P=0.31$, respectively) (Fig. 1).

\section{Prevalence of HBV, HCV, and HIV in Patients with UC}

Among the 581 patients with UC, 2.2\% (12/541) had HBV, 1.7\% (9/517) had HCV, and 0.2\% (1/499) had HIV. Again, these rates did not differ significantly from the corresponding rates in the general population $(P=0.07, P=0.09$, and $P=0.68$, respectively).

Of the 21 patients with UC and concomitant $\mathrm{HBV} / \mathrm{HCV}$ infection, 14 (66.7\%) received steroids and eight (38\%) received azathioprine (AZA) or 6-mercaptopurine (6-MP). Five developed cirrhosis (23.8\%), and one patient with HCV infection died of acute on chronic liver failure (ACLF) (Table 1).

\section{Prevalence of HBV, HCV, and HIV Infection in Patients with CD}

Among the 327 patients with CD, 2.8\% (8/288) had HBV and $0.7 \%(2 / 273)$ had HCV; no patient had HIV, while one patient had HBV and HCV coinfection. The prevalence of $\mathrm{HBV}$ and HCV in patients with CD was not significantly different compared to that in the general population $(P=0.41$ and $P=0.65$, respectively).

Three patients with CD (33.3\%) diagnosed with HBV/HCV infection received steroids, while three (33.3\%) received AZA or 6-MP. Of the nine patients with HBV/HCV infection, one developed cirrhosis (11.1\%). Additionally, one patient with HBV died of ACLF (Table 2).

Table 1. Demographic and Clinical Characteristics of Patients with UC and Concomitant Viral Infections

\begin{tabular}{|c|c|c|c|}
\hline Characteristic & HBV $(n=12)$ & $\mathrm{HCV}(\mathrm{n}=9)$ & HIV $(n=1)$ \\
\hline Median age (yr) & 35 (24-65) & $36(28-52)$ & 38 \\
\hline \multicolumn{4}{|l|}{ Sex } \\
\hline Male & $8(66.7)$ & $4(44.4)$ & - \\
\hline Female & $4(33.3)$ & $5(55.6)$ & $1(100)$ \\
\hline Median duration of UC (yr) & $7.0(2.5-14.0)$ & $4.5(1.5-15.0)$ & 5 \\
\hline \multicolumn{4}{|l|}{ Extent $^{\mathrm{a}}$} \\
\hline E1 & None & $2(22.2)$ & $1(100)$ \\
\hline E2 & $7(58.3)$ & $4(44.4)$ & - \\
\hline E3 & $5(41.7)$ & $3(33.3)$ & - \\
\hline \multicolumn{4}{|l|}{ Disease course of UC } \\
\hline Single episode & $3(25.0)$ & $2(22.2)$ & $1(100)$ \\
\hline Chronic continuous & None & None & - \\
\hline Intermittent relapses & $8(66.7)$ & $6(66.7)$ & - \\
\hline Fulminant & $1(8.3)$ & $1(11.1)$ & - \\
\hline Immunosuppression & & & None \\
\hline Steroids & $9(75.0)$ & $5(55.6)$ & - \\
\hline AZA/6-MP & $5(41.7)$ & $3(33.3)$ & - \\
\hline Anti-TNF- $\alpha$ & None & $1(11.1)$ & - \\
\hline Liver disease outcome & & & None \\
\hline Cirrhosis & $3(25.0)$ & $2(22.2)$ & - \\
\hline ACLF & None & $1(11.1)$ & - \\
\hline Liver-related mortality & None & 1 (11.1), ACLF & None \\
\hline
\end{tabular}

Values are present as number (\%).

${ }^{a}$ The Montreal classification was used to classify the disease extent of UC. ${ }^{6}$

HIV, human immunodeficiency virus; AZA, azathioprine; 6-MP, 6-mercaptopurine; anti-TNF- $\alpha$, anti-tumor necrosis factor- $\alpha$; ACLF, acute on chronic liver failure. 
Table 2. Demographic and Clinical Characteristics of Patients with CD and Concomitant Viral Infections

\begin{tabular}{|c|c|c|}
\hline Characteristic & HBV $(n=8)$ & $\operatorname{HCV}(n=2)$ \\
\hline Median age (yr) & $48(21-69)$ & $53(37-69)$ \\
\hline \multicolumn{3}{|l|}{ Sex } \\
\hline Male & $7(87.5)$ & $1(50)$ \\
\hline Female & $1(12.5)$ & $1(50)$ \\
\hline Median duration of CD (yr) & $4.5(2.5-9.0)$ & $7.0(5.0-9.0)$ \\
\hline \multicolumn{3}{|l|}{ Age at diagnosis $^{a}$} \\
\hline A1 & $1(12.5)$ & None \\
\hline A2 & $2(25.0)$ & $1(50.0)$ \\
\hline A3 & $5(62.5)$ & $1(50.0)$ \\
\hline \multicolumn{3}{|l|}{ Location } \\
\hline L1 & $1(12.5)$ & None \\
\hline L2 & $5(62.5)$ & $1(50.0)$ \\
\hline L3 & $2(25.0)$ & None \\
\hline$\llcorner 4$ & None & $1(50.0)$ \\
\hline \multicolumn{3}{|l|}{ Behavior } \\
\hline B1 & $5(62.5)$ & $1(50.0)$ \\
\hline B2 & $3(37.5)$ & $1(50.0)$ \\
\hline B3 & None & None \\
\hline p & None & None \\
\hline \multicolumn{3}{|l|}{ Immunosuppression } \\
\hline Steroids & $3(37.5)$ & $1(50.0)$ \\
\hline AZA/6-MP & $3(37.5)$ & $1(50.0)$ \\
\hline Anti-TNF- $\alpha$ & None & None \\
\hline \multicolumn{3}{|l|}{ Liver disease outcome } \\
\hline Cirrhosis & $1(12.5)$ & None \\
\hline ACLF & $1(12.5)$ & None \\
\hline Liver-related mortality & 1 (12.5), ACLF & None \\
\hline
\end{tabular}

Values are present as number (\%).

${ }^{a}$ The Montreal classification was used to classify the clinical characteristics of $\mathrm{CD}{ }^{6}$

AZA, azathioprine; 6-MP, 6-mercaptopurine; anti-TNF- $\alpha$, anti-tumor necrosis factor- $\alpha ; A C L F$, acute on chronic liver failure.

\section{Prevalence of Viral Infections among Patients with IBD by Age Group}

The prevalence of the viral infections in patients with IBD was also examined according to age. None of the patients (UC or CD) aged less than 20 years were found to have these viral infections. Further, no statistically significant differences in the prevalence of these infections were found among different age groups (Table 3 ).
Table 3. Prevalence of Viral Infections in Patients with IBD according to Age (Age-Stratified Analysis)

\begin{tabular}{cccccc}
\hline \multirow{2}{*}{ Age (yr) } & \multicolumn{2}{c}{ UC } & & \multicolumn{2}{c}{ CD } \\
\cline { 2 - 3 } \cline { 5 - 6 } & HBV (n=12) & HCV (n=9) & & HBV (n=8) & HCV (n=2) \\
\hline $10-20$ & $0 / 30(0)$ & $0 / 29(0)$ & & $0 / 17(0)$ & $0 / 16(0)$ \\
$21-30$ & $4 / 140(2.9)$ & $1 / 132(0.8)$ & & $3 / 74(4.1)$ & $0 / 69(0)$ \\
$31-40$ & $5 / 184(2.7)$ & $5 / 176(2.8)$ & & $0 / 73(0)$ & $1 / 66(1.5)$ \\
$41-50$ & $1 / 117(0.9)$ & $2 / 114(1.8)$ & & $1 / 61(1.6)$ & $0 / 58(0)$ \\
$51-60$ & $1 / 45(2.2)$ & $1 / 42(2.4)$ & & $2 / 39(5.1)$ & $0 / 38(0)$ \\
$>60$ & $1 / 25(4.0)$ & $0 / 24(0)$ & & $2 / 24(8.3)$ & $1 / 26(3.8)$ \\
$P$-value & 0.77 & 0.70 & 0.23 & 0.37 \\
\hline
\end{tabular}

Values are present as number (\%).

\section{Disease Controls}

Patients with ITB ( $\mathrm{n}=95$ ) were considered as disease controls. The prevalence of HBV, HCV, and HIV in this group was $5.9 \%(4 / 67), 1.8 \%(1 / 57)$, and $1.2 \%(1 / 84)$, respectively, and these rates for HCV and HIV were not significantly different from the corresponding rates in patients with IBD. In contrast, $\mathrm{HBV}$ was found to be more prevalent in patients with ITB than in those with IBD $(P=0.04)$.

\section{DISCUSSION}

In current study, we found that the prevalence of HBV, $\mathrm{HCV}$, and HIV infections did not differ between patients with IBD and the general population in India.

He et al. ${ }^{7}$ determined that the prevalence of $\mathrm{HBV}$ infection (HBsAg positivity) in patients with CD and UC was $13.6 \%$ (61/449) and $16.8 \%$ (38/226), respectively, in a similar study, and they found no difference in prevalence compared to that of the general population in southern China, which is a highly endemic area for HBV and HCV. Studies have reported the prevalence of $\mathrm{HBV}$ infection in IBD patients to vary from $0.6 \%$ to $3.7 \% .^{8-14}$ Some of these studies have also reported a higher prevalence of $\mathrm{HBV}$ infection in patients with IBD than in the general population, while some have reported no such difference. Our findings showed that the HBV prevalence in patients with IBD was $2.2 \%$ for those with UC and $2.8 \%$ for those with $\mathrm{CD}$, which was lower than the prevalence in the general population but not significantly. A possible explanation for our findings could be that most patients at our center were from north India, which has a relatively lower prevalence of HBV than south or east India. The distribution of HBV in India is highly heterogeneous, with tribal popula- 
tions from southern states showing a very high prevalence $(>20 \%) .^{15}$

Another finding of the current study was that HBV was significantly more prevalent in patients with ITB (5.9\%) than in those with IBD $(2.4 \%)(P=0.04)$. This finding is consistent with those of previous studies, which found HBV to be more prevalent in patients with tuberculosis with or without concomitant HIV infection. In a study from the United Kingdom, the prevalence of $\mathrm{HBV}$ was $2.6 \%$ in patients with tuberculosis, which was significantly higher than the national prevalence of $0.3 \%{ }^{16}$ Another study from Brazil shown that the HBV seroprevalence in patients with tuberculosis without HIV was $14.6 \%{ }^{17}$

The prevalence of HCV infection in the patients with UC and CD in the current study was $1.7 \%$ and $0.7 \%$, respectively, and it was not different from the prevalence in the general population. Biancone et al. ${ }^{10}$ reported that the HCV prevalence in patients with CD in their study was $7.4 \%$, and this was higher than that in the normal healthy controls in Italy. In a Chinese study, the prevalence of HCV infection was found to be $1.64 \%$ in patients in IBD, and this rate was higher than the reported prevalence in southern China. ${ }^{18}$ Then, a study from France reported a higher prevalence of HCV infection (5.98\%) in patients with IBD than in the general population, ${ }^{19}$ and a Spanish study found that $1.59 \%$ of patients with UC and $0.79 \%$ of patients with CD tested positive for anti-HCV antibodies. ${ }^{12}$

Thus far, HIV in IBD has not been well described, and only case series and case reports are available on this subject. In our study as well, only one patient with UC had HIV infection, but no patient with CD did.

To our knowledge, this is the first study to describe the prevalence of $\mathrm{HBV}, \mathrm{HCV}$, and HIV infections in patients with IBD from India. The limitations of this study are that it is a retrospective study and all three viral markers of all the patients were not available for analysis. Additionally, the viral markers were examined only at baseline at the first presentation, and it is unclear what effect repeated testing would have had on the prevalence rates. However, the retrospective design should not affect the results as the data were prospectively maintained and data were collected from documented reports.

In conclusion, the prevalence of HBV, HCV, and HIV infection in patients with $\operatorname{IBD}(2.4 \%, 1.4 \%$, and $0.1 \%$, respectively) from north India was not found to differ from the corresponding prevalence in the general population. Nevertheless, management of such infections in IBD is very challenging given that these patients generally receive immunosuppres- sive therapy. The high risk of flare if these viral infections go undetected mandates routine screening of patients with IBD for $\mathrm{HBV}, \mathrm{HCV}$, and HIV.

\section{REFERENCES}

1. Ahuja V, Tandon RK. Inflammatory bowel disease: the Indian augury. Indian J Gastroenterol 2012;31:294-296

2. Gisbert JP, Chaparro M, Esteve M. Review article: prevention and management of hepatitis $\mathrm{B}$ and $\mathrm{C}$ infection in patients with inflammatory bowel disease. Aliment Pharmacol Ther 2011;33:619-633.

3. Viazis N, Vlachogiannakos J, Georgiou O, et al. Course of inflammatory bowel disease in patients infected with human immunodeficiency virus. Inflamm Bowel Dis 2010;16:507-511.

4. National HIV counseling and testing services (Hcts) guidelines. National AIDS Control Organization Website. http://naco.gov. in/sites/default/files/National\%20HIV\%20Counselling\%20 \%26\%20Testing\%20Services\%20Guideline,\%20Dec\%202016. pdf.

5. Hepatitis in India: burden, strategies and plans. National Centre for Disease Control Web site. http://www.ncdc.gov.in/writereaddata/linkimages/NewsLtr0103_20146480274026.pdf. Accessed February 24, 2014.

6. Satsangi J, Silverberg MS, Vermeire S, Colombel JF. The Montreal classification of inflammatory bowel disease: controversies, consensus, and implications. Gut 2006;55:749-753.

7. He Y, Xu P, Chen Y, et al. Prevalence and influences of hepatitis $B$ virus infection on inflammatory bowel disease: a retrospective study in southern China. Int J Clin Exp Med 2015;8:80788085 .

8. Tolentino YF, Fogaca HS, Zaltman C, Ximenes LL, Coelho HS Hepatitis B virus prevalence and transmission risk factors in inflammatory bowel disease patients at Clementino Fraga Filho University Hospital. World J Gastroenterol 2008;14:3201-3206.

9. Esteve M, Saro C, González-Huix F, Suarez F, Forné M, Viver JM. Chronic hepatitis B reactivation following infliximab therapy in Crohn's disease patients: need for primary prophylaxis. Gut 2004;53:1363-1365.

10. Biancone L, Pavia M, Del Vecchio Blanco G, et al. Hepatitis B and $\mathrm{C}$ virus infection in Crohn's disease. Inflamm Bowel Dis 2001;7:287-294

11. Chevaux JB, Nani A, Oussalah A, et al. Prevalence of hepatitis $\mathrm{B}$ and $\mathrm{C}$ and risk factors for nonvaccination in inflammatory bowel disease patients in northeast France. Inflamm Bowel Dis 2010;16:916-924. 
12. Loras C, Saro C, Gonzalez-Huix F, et al. Prevalence and factors related to hepatitis $\mathrm{B}$ and $\mathrm{C}$ in inflammatory bowel disease patients in Spain: a nationwide, multicenter study. Am J Gastroenterol 2009;104:57-63.

13. Park SH, Yang SK, Lim YS, et al. Clinical courses of chronic hepatitis B virus infection and inflammatory bowel disease in patients with both diseases. Inflamm Bowel Dis 2012;18:20042010 .

14. Papa A, Felice C, Marzo M, et al. Prevalence and natural history of hepatitis $\mathrm{B}$ and $\mathrm{C}$ infections in a large population of IBD patients treated with anti-tumor necrosis factor-alpha agents. J Crohns Colitis 2013;7:113-119.

15. Puri P. Tackling the hepatitis B disease burden in India. J Clin Exp Hepatol 2014;4:312-319.
16. Nooredinvand HA, Connell DW, Asgheddi M, et al. Viral hepatitis prevalence in patients with active and latent tuberculosis. World J Gastroenterol 2015;21:8920-8926.

17. Blal CA, Passos SR, Horn C, et al. High prevalence of hepatitis $B$ virus infection among tuberculosis patients with and without HIV in Rio de Janeiro, Brazil. Eur J Clin Microbiol Infect Dis 2005;24:41-43.

18. Li YD, Lin JJ, Zheng SS. Inflammatory bowel diseases and hepatitis C virus infection. Hepatobiliary Pancreat Dis Int 2010;9:398-401.

19. Longo F, Hebuterne X, Tran A, et al. Prevalence of hepatitis C in patients with chronic inflammatory bowel disease in the region of NICE and evaluation of risk factors. Gastroenterol Clin Biol 2000;24:77-81. 